\title{
Examination of car navigation systems and $U X$ designs - suggestion for a new interface
}

\author{
Fanni Vörös ${ }^{\mathrm{a},}$ *, Zoltán Tompos ${ }^{\mathrm{b}}$, Béla Kovács ${ }^{\mathrm{a}}$ \\ ${ }^{a}$ ELTE Eötvös Loránd University, Dept. of Cartography and Geoinformatics, Budapest, Hungary, vorosfanni@map.elte.hu, \\ climbela@map.elte.hu \\ ${ }^{b} N N G$ Ltd., Budapest, Hungary, zoltan.tompos@nng.com \\ * Corresponding author
}

\begin{abstract}
The need for car-related navigation and the appearance of the vehicles themselves are much the same age - of course. In the early days, paper maps and personal questioning were solved this problem. Nearly 100 years ago, the first built-in car GPS was released - and this is an innovation that is still an important part of car design. Planning the user interface is a very exciting issue, because only in a few seconds the display needs to provide the user with the right amount of information. In this research our goal was to assess Hungarians driving and built-in GPS using habits and based on this try to suggest the "perfect" interface. A questionnaire was made with 19 or 46 questions and more than 1000 respondents completed it. Because of the high number of questions only selected diagrams are represented. Some answers have also been subjected to different statistical tests.
\end{abstract}

Keywords: Car Navigation System, UX design, Questionnaire, Survey, Built-in car GPS

\section{Introduction}

Nowadays, it is not a problem anymore to find the best way to get from A to B. If you are uncertain, you only have to do is to ask the navigation system for help. There are countless offers to choose from, and they are no longer so expensive as a few years ago, so anyone can find the right model for their wallets and needs. Obviously, there are people who are still taking traditional paper-based maps if they are uncertain about navigation, but their number is decreasing. The help can come in the form of a mobile phone app, PDA (Personal Digital Assistant) / PNA (Portable Navigation Assistant) or built-in GPS Navigation System. Naturally, car navigation systems have to fulfil claims other than e.g. route planners presenting public transport situations. For safe driving, the driver will not watch the display for more than two or three seconds. In order to give the driver relevant information in terms of navigation it is really needed to plan how much information is displayed on the screen and in what quality. Here you have to think not only about the map itself which is mostly not very nice from a cartographic point of view -, but about the information and buttons that help to react quickly to changes during driving.

\section{Overview of GPS In-Car Navigation history}

Everything started in 1930 with Iter Avto (Fig. 1). This was the world's first automobile navigator developed by Touring Club Italiano. It did not give voice instructions and directions and it did not use satellites yet. It had a simple principle: the screen scrolled paper maps manually that were attached to a cable, which was similar to a modern mechanical speedometer. So the scroll rate of the map was proportional to the vehicle's speed. The problem was that if the driver made a turn, he would have to load a new map and find it on his current location.

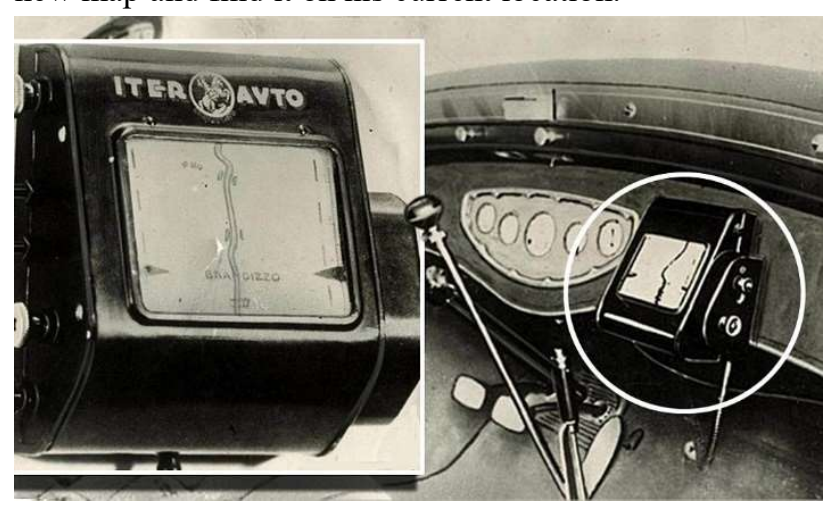

Figure 1. Iter Avto (dailymail.co.uk)

Before GPS there were a few car tracking and navigation systems. Driver Aid, Information \& Routing (DAIR) was introduced in 1966 by General Motors. It was capable to alert the driver to signs, speed limits, and hazards along the route. Inertial navigation systems (1981) operated a small helium gas gyroscope. The system used polar coordinate system formulas: if the driver knew the pole, azimuth and radius, the position could be counted. The big shift occurred when GPS technology appeared, which was developed by the United States and used it for military purposes at the beginning. In 1983, president Ronald Reagan signed an executive order that allowed civils to use the system. In 1990, Mazda released the first automobile that had a built-in GPS system, and two years later voiceassisted GPS appeared in the Toyota Celsior. The U.S. government made the publicly-available version of the GPS even more accurate in 2000. From that moment, car GPS systems became available worldwide. More and more 
automakers, companies and tech giants step into the automotive GPS market.

\section{NNG}

NNG is a company, which developed the groundbreaking iGO Navigation Engine, which has separated itself as the leading car navigation product across all global markets and all car segments (Fig. 2). It was founded by Hungarian technology experts with the help of two Israeli businessmen. Their goal was simple: to create a more userfriendly and nicer navigation solution than what was available on the market that time. At present, seven of the world's top ten car manufacturers are using its solutions and are present in more than 30 car brands.

\section{NNG}

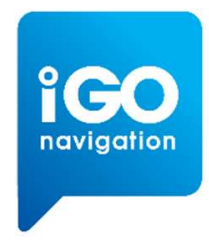

Figure 2. NNG and iGO logo

\section{UX meaning}

The phrase "user experience" is associated with an extensive meaning (ForLIZZI and BATTARBEE, 2004). According to ALBEN (1996), "experience" means the aspects of the way of people using interactive products: the feeling of possessing, feeling about it while they are using it, how well it serves their purposes, the understanding how it works and how well it fits into the entire context in which they are using it. UX is a consequence of a user's internal state (expectations, needs, motivation, mood, etc.), the characteristics of the designed system (includes all products, services, and infrastructures that are involved in the interaction when using the examined product) and the context (or the environment) within which the interaction occurs (HASSENZAHL and TRACTINSKY, 2006; ROTO, 2006). UX is subjective: user's state affects the system perception, which in turn affects the experience and user's state (Fig. 3).

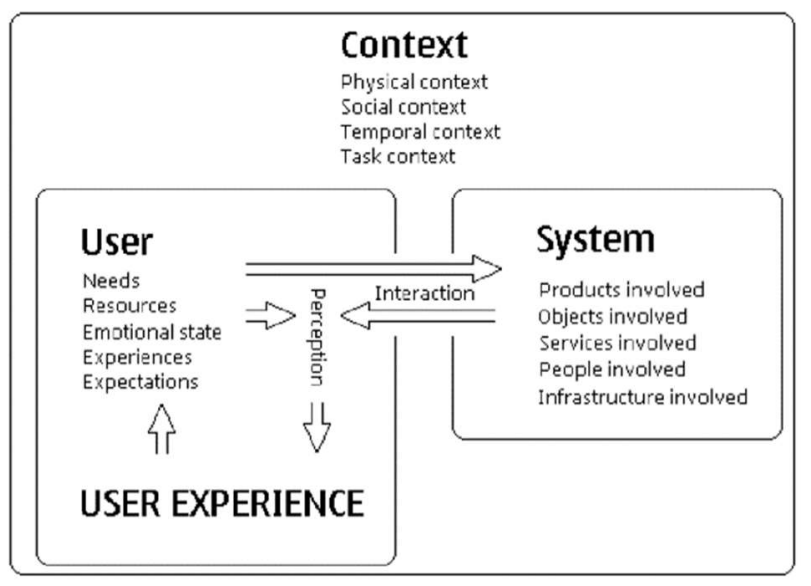

Figure 3. User experience building blocks (ROTO, 2006)

In-vehicle GPS navigation systems have the potential of affecting the interaction of users with their environment in profound and complex ways. Empirical and theoretical analyses demonstrate that use of GPS units changes how people interpret, learn, navigate, and experience spaces and places. Navigation using GPS is based on abstract representations of spaces and places (LESHED et al., 2008).

\section{The questionnaire}

The main steps of our research were to examine Hungarian user navigation habits, to assess user needs (based on representative questionnaires) and based on the results to suggest a new car navigation interface. A similar questionnaire has already been prepared by NNG with the involvement of 109 people eight years ago with 153 questions (VARGA, 2011). Knowing this study, we created our own questionnaire with 19 or 46 questions (see below) and more than 1000 people completed it. The most popular interface for this kind of questionnaires is Google Forms, so we have chosen it too.

The first part of the questionnaire - mandatory for everyone - was about general, personal questions. We were curious about the respondents age, sex, education level, residency. We wanted to know information about the used car, driving habits, what is he/she thinks about autonomous cars, and - finally - if there is a built-in GPS in the car and if it is used.

If the answer was a "no" for the last question, we asked only three other things: why they not use it, what else is used, and in which case would they use the built-in GPS. We have given them responses, but many have written their own opinions.

Essential questions were asked after the "yes" answer. We asked them about how they navigate with the GPS and how the GPS navigates them (language, view on the display, input mode). We asked questions about the updating habits, the night mode, alternative routes, POIs. In which situations do they use it (during driving? for what reason?), do they use additional navigation device? Finally, we were curious to see what the users see/want to see in their own GPS map view (what features they would like to achieve with one click).

\section{Statistical tests}

We wanted to support our results statistically. If the data is not a normal distribution set, other tests should be used (not t-test).

\subsection{Mann-Whitney test}

The most common statistical test is t-test that can only be applied to a standard data set. In the present case, however, most of the data series to be compared are considerably different in size, so we chose the nonparametric equivalent of the two-sample t-test used for non-standard distribution and ordinal (sorted) variables. The Mann-Whitney test is especially used to compare groups with a small number of elements. It can be used to determine whether two independent samples were selected from populations having the same distribution. We calculated value $\mathrm{p}$; if the significant level is under 0.05 , the null hypothesis of the different originating distributions is accepted (VÖRÖS et al., 2018). 


\subsection{Chi-squared test}

\subsubsection{Pearson's test}

Pearson's chi-squared test $(\chi 2)$ is the most widely used of many chi-squared tests. It is a suitable statistical method for testing discrete (nominal) variables. It is a basic requirement that an entity (person, thing, etc.) should belong to one category. The essence of the test is to calculate first the expected distribution if there are no differences between the attributes of the variables (that is, the null hypothesis would be valid). Then this distribution is compared to the real (observed) distribution. The difference of deviation should be significant.

\subsubsection{Fisher's exact test}

Fisher's exact test is a statistical significance test that belongs to non-parametric procedures and is used in analysing contingency tables. It measures the strength of the relationship between two dichotomous variables and tests independence. Its application is recommended for small samples, because in the case of a small number of elements the sample distribution of the test statistic under the null hypothesis is generally not $\chi 2$. Thus, a statistical decision based on this distribution will not be correct. However, it can be used on a larger sample too.

\section{Results}

\subsection{General results}

As mentioned before, more than 1000 people completed the questionnaire. $64-36 \%$ was the men-women proportion. We have created six age groups: under 25 (16\%), 25-35 (33\%), 36-45 (22\%), 46-55 (16\%), 56-65 $(8 \%)$ and above 65 years (5\%). 36\% of the respondents are from the capital city, $28 \%$ from county seats, $24 \%$ from other cities and $12 \%$ are villagers. Most of them (70\%) have higher education, the rest has secondary or primary education. $21 \%$ of the respondents have a new car, the others bought a used car or do not use their own car. Thanks to the latter two, the average car age is 12.5 years (Fig. 4). According to ACEA REPORT (2018), this age is 2 years more than the European average.

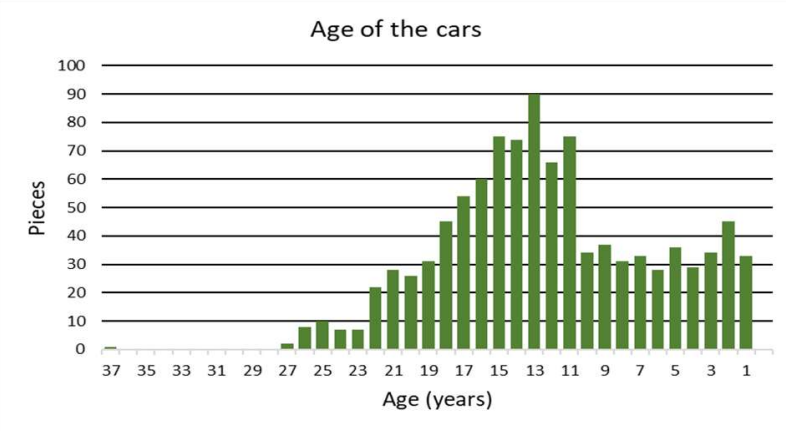

Figure 4. Age distribution of the cars

The most common car brands are Ford, Opel, Renault, Suzuki, Toyota, Volkswagen, but we had Audi, BMW, Chrysler, Lexus, and Tesla too. We were curious about the respondents' relationship with autonomous cars; roughly half of them are aware that at which level we are now. Nevertheless, $61 \%$ would not use self-driving cars if they had no financial limit. Overall, only $17 \%$ of drivers have built-in GPS in their car and merely 10\% use it (Fig. 5).

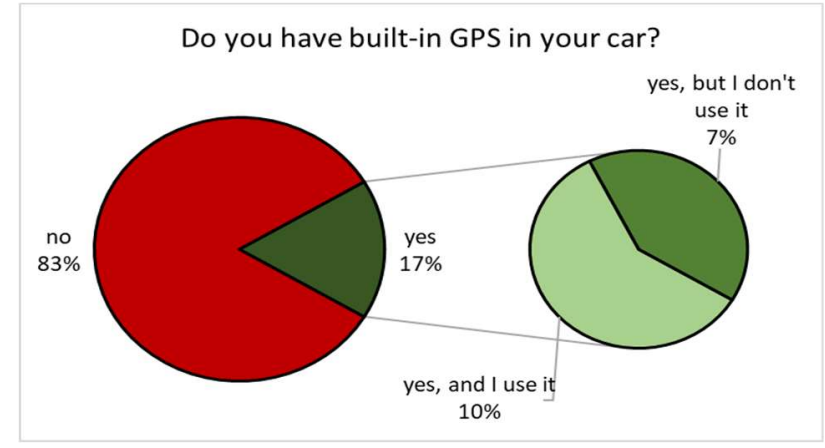

Figure 5. Proportion of built-in GPS users

We divided the cars into two groups: the first group contains cars (ages) that do not have built-in GPS, the second group's cars have. With the help of the MannWhitney test, it can be said that the two groups differ significantly, $p<0.0001$, so the null hypothesis is accepted. As expected, mostly young people drive used cars or they do not own a car, and the number of their own vehicles is increasing with age. According to the questionnaire it can be said that the older you are, the more you have and use the GPS (Fig. 6).

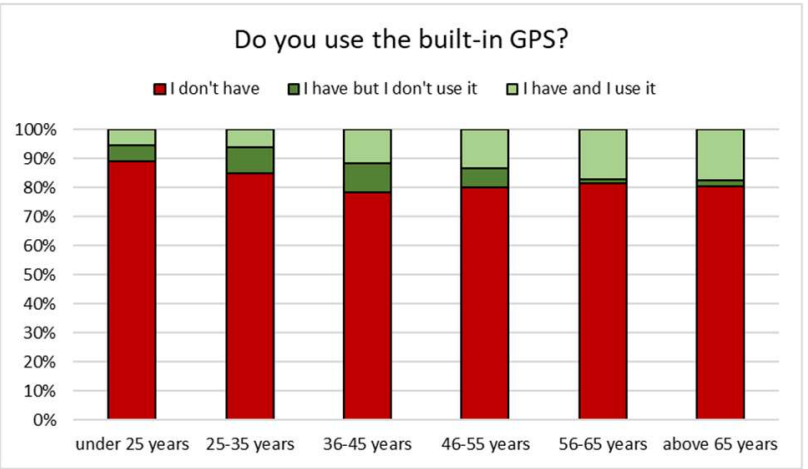

Figure 6. Proportion of built-in GPS users according to age groups

We wanted to know if there is some relationship between the age of the car and the rate of use. We granted the aforementioned three possibilities: used car, new car, has no car. According to the statistical test it can be said that the age of the used cars is significantly different from the new ones and the age of the non-private cars (Table 1).

\begin{tabular}{|c|c|c|c|}
\hline $\begin{array}{c}\text { Is it } \\
\text { used? }\end{array}$ & yes & no & has no car \\
\hline yes & - & $<.0001$ & $<.0001$ \\
\hline no & $<.0001$ & - & 0.0673 \\
\hline has no car & $<.0001$ & 0.0673 & - \\
\hline
\end{tabular}

Table 1. $p$ values of the cars' rate of use, significant differences in red $(\mathrm{p}<0.05)$

\subsection{Who do not use built-in GPS}

From the average age of the vehicles it was suspected that the most answers for the question "why do not you use built-in GPS?" would be "I bought a used car, it was not in 
it" or "there was no option for built-in GPS when shopping". Besides that, the users had problems with GPS's price and obsolescence. It is a general belief that mobile applications are much better (free, has traffic data), $65 \%$ rather use it. Nevertheless, few are those who have bought the GPS but do not use it because they are complicated, or have not even tried it. Almost $70 \%$ of the respondents said they would use built-in GPS if they had free installation and/or upgrade. About $10 \%$ would not use it under any circumstances. Most often drivers are navigating with the help of a paper map or other person else apart their mobile phone. The others (10\%) use PDA/PNA and other tools (memory, carplay).

\subsection{Who use built-in GPS}

It can be observed that people with higher and secondary education use built-in GPS, first of all those (70\%) who drive more than 10,000 kilometres per year.

In the questionnaire, several questions were related to driving habits in certain situations. Since the definition of the situations would take a lot of space, we will replace them with numbers (Table 2).

\begin{tabular}{|c|c|}
\hline Situation & Driving environment \\
\hline 1 & $\begin{array}{l}\text { Everyday routes within the city } \\
\text { (e.g. Workplace) }\end{array}$ \\
\hline 2 & $\begin{array}{l}\text { Everyday routes between cities } \\
\text { (e.g. commuting to work) }\end{array}$ \\
\hline 3 & Other routes within the city \\
\hline 4 & Other routes between cities \\
\hline 5 & Weekend trips \\
\hline 6 & Domestic holidays \\
\hline 7 & Holidays abroad \\
\hline 8 & Other abroad trips \\
\hline
\end{tabular}

Table 2. Matching situations with numbers

Figure 7 shows how often the respondents drive in different situations. If we compare the diagram with Figure 8 , there is a clear tendency to contradict each other. This contrast is absolutely logical: the more often a person drives in a situation, the better he/she knows the route and the less a navigation device is needed.

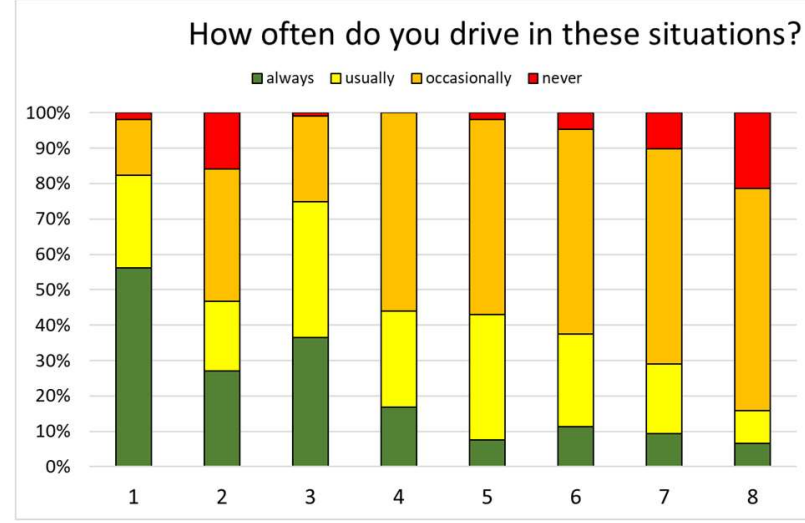

Figure 7. Frequency of driving in different situations

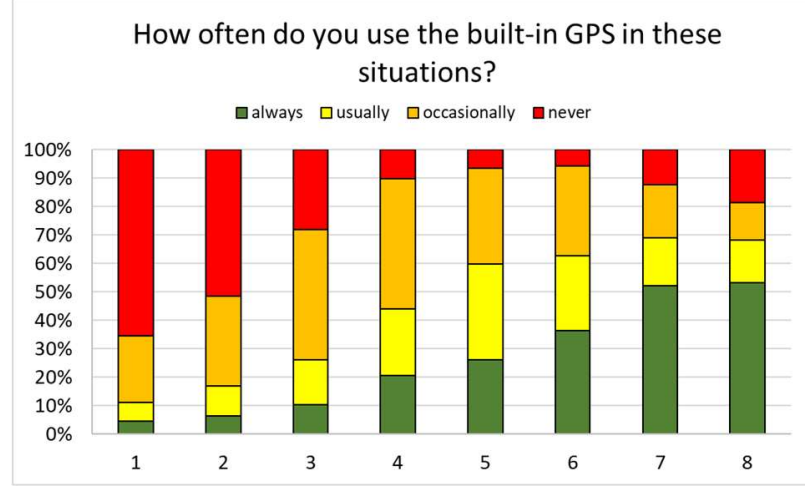

Figure 8. Frequency of using built-in GPS in different situations

Most of them used to use perspective view facing the north. Currently the GPS is in the usual place (option 4 in Fig. 9) in $66 \%$ of the cases. We asked the driver if he/she could choose where he/she would place the GPS. Interestingly, the answers were divided equally between options 2 and 5 .

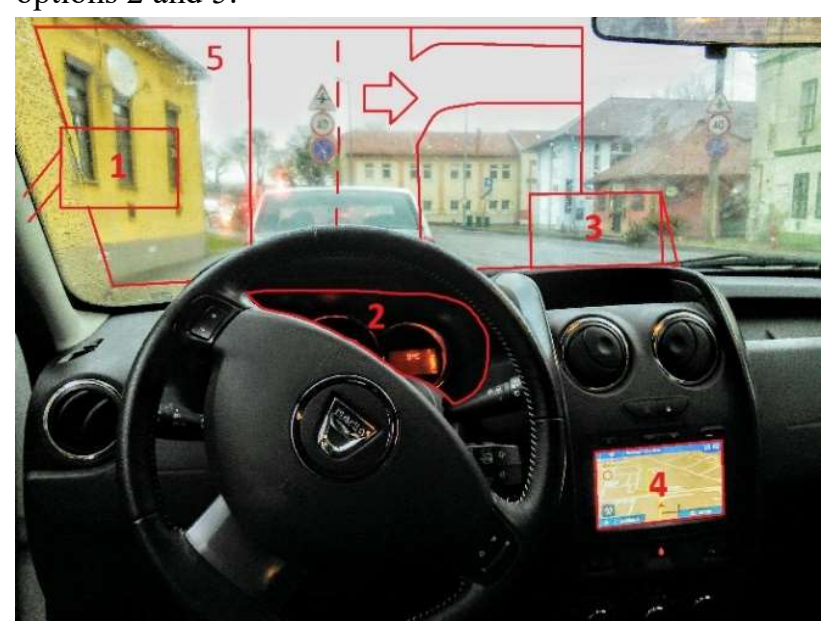

Figure 9. Possible placements of a built-in GPS

Half of the systems speak Hungarian to the user, $17 \%$ do not speak at all and the rest speaks other language. Interestingly, statistically there is no correlation between the used language used and the rate of use: we can state that probably only the GPSs that "speak in another language (but knows Hungarian)" are in used cars. Other user habits have also emerged. They almost always look at 
the alternative routes offered by the system. Half of people do not enter more than one POI (Points of Interest). Although $60 \%$ of users update the system (Figure 10), only $23 \%$ of them do it more regularly than a year.

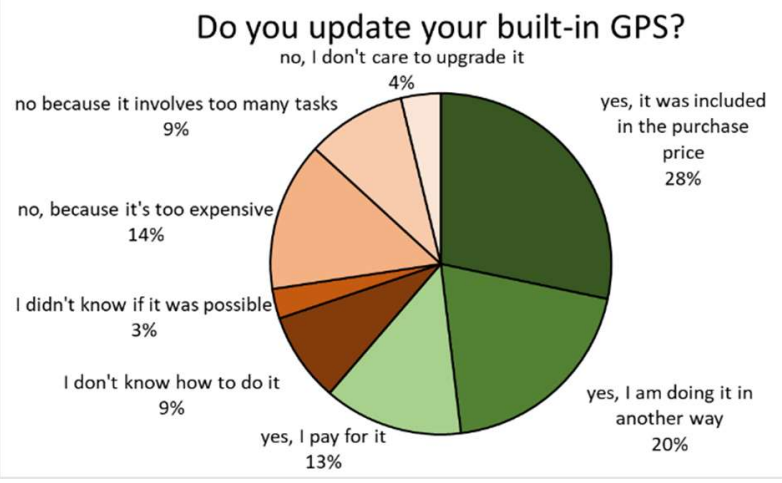

Figure 10. Update habits

Figure 11 is related to Figures 7 and 8. In a familiar, everyday environment, they do not have to plan route. It can also be seen that the farther you travel, the more you plan it.

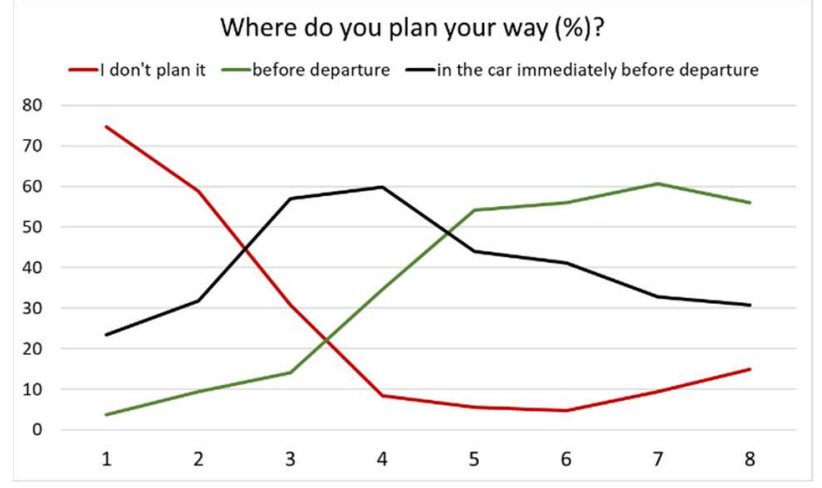

Figure 11. Road planning habits in different situations

In Figure 12 we can see what other applications the drivers use besides their built-in navigation. In axis $\mathrm{x}$ there are the driving environments, in axis y the applications, maps. The colouring depends on what percentage of the respondents has chosen the application in each case. Not surprisingly, most of the drivers use Google Maps and Waze in addition to the cars' GPS, but not a negligible number of them use paper maps or nothing at all.
In addition to the built-in GPS, what other navigations do you use in these situations (\%)?

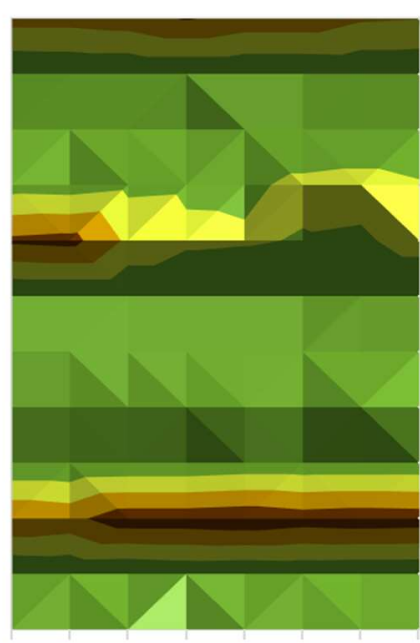

Waze
TomTom GO
Sygic
Paper map
Nothing
Navmii
MAPS ME
iGO
HERE WeGo
Google Maps
Garmin
Apple Maps

$$
\begin{array}{rrrrrrrrr}
1 & 2 & 3 & 4 & 5 & 6 & 7 & 8 & \\
& \square-10 & \square & 10-20 & \square & 20-30 & \square-30-40
\end{array}
$$

Figure 12. Other applications used besides the built-in GPS

We were curious as to how gender and age affect driving and GPS usage habits. As expected, women are more likely to plan their trips, in particular from home, and not in the car before departure. "Farther" routes (driving environments 5-8) are significantly more often planned ( $p=0.025)$ by them than men. Therefore, the built-in GPS is significantly less used $(p=0.00001)$ by women in the same driving situations. If the use of the interface is needed while driving, women tend to pull over to the side more often than men (Figure 13). Women only write 1 POI at a time, or if they need more, they do it in advance.

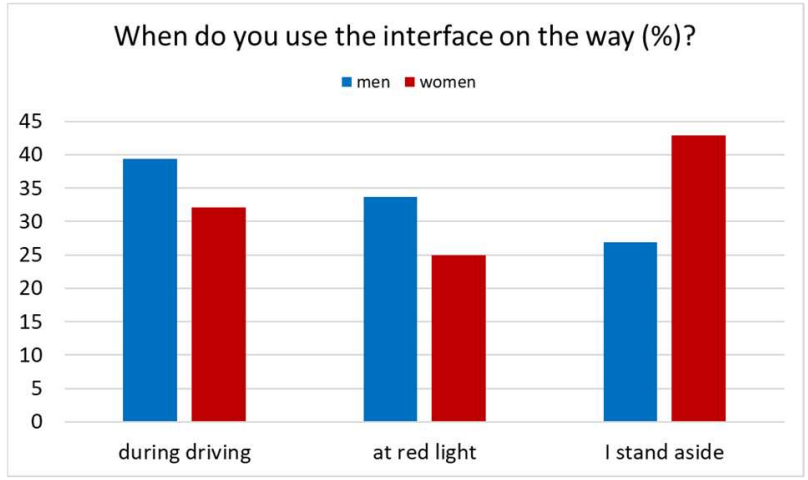

Figure 13. GPS usage habits while driving

Another interesting aspect is examining the age groups. As shown before (Figure 6), the number of GPS receivers and users increases with age. It can be seen in Figure 14 how the percentage of GPS updates according to aging changes: 77-54-60-43-75-88\%. Interestingly, those over the age of 56 are aware of how they can update and the fact that they can do it at all. 


\section{Do you update your built-in GPS?}

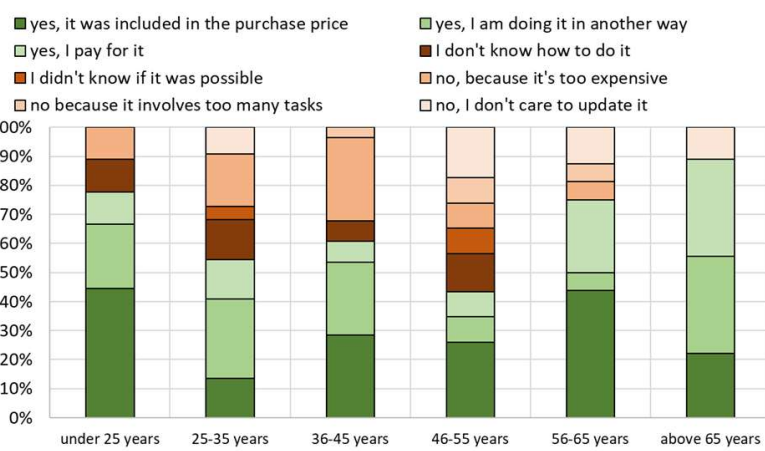

Figure 14. Update habits according to age groups

We examined whether there is a statistical difference between age groups and update habits (update?: yes / no). According to the test, only the 46-55 age group and those over the age of 65 differ significantly in their update habits. In other cases, there is no difference, and even the habits of those under the age of 25 are the same as those of the 56-65 and 65+ age groups.

\begin{tabular}{|c|c|c|c|c|c|c|}
\hline Age & $\begin{array}{c}\text { under } \\
25\end{array}$ & $\begin{array}{c}25- \\
35\end{array}$ & $\begin{array}{c}36- \\
45\end{array}$ & $\begin{array}{c}46- \\
55\end{array}$ & $\begin{array}{c}56- \\
65\end{array}$ & $\begin{array}{c}\text { above } \\
65\end{array}$ \\
\hline $\begin{array}{c}\text { under } \\
25\end{array}$ & - & 0.41 & 0.44 & 0.12 & 1 & 1 \\
\hline $25-35$ & 0.41 & - & 0.77 & 0.55 & 0.3 & 0.1 \\
\hline $36-45$ & 0.44 & 0.77 & - & 0.26 & 0.51 & 0.22 \\
\hline $46-55$ & 0.12 & 0.55 & 0.26 & - & 0.09 & 0.04 \\
\hline $56-65$ & 1 & 0.3 & 0.51 & 0.09 & - & 0.62 \\
\hline $\begin{array}{c}\text { above } \\
65\end{array}$ & 1 & 0.1 & 0.22 & 0.04 & 0.62 & - \\
\hline
\end{tabular}

Table 3. $p$ values of the update habits (yes/no) according to age groups, significant differences in red $(p<0.05)$

\section{What do you want/do not want in your map view?}

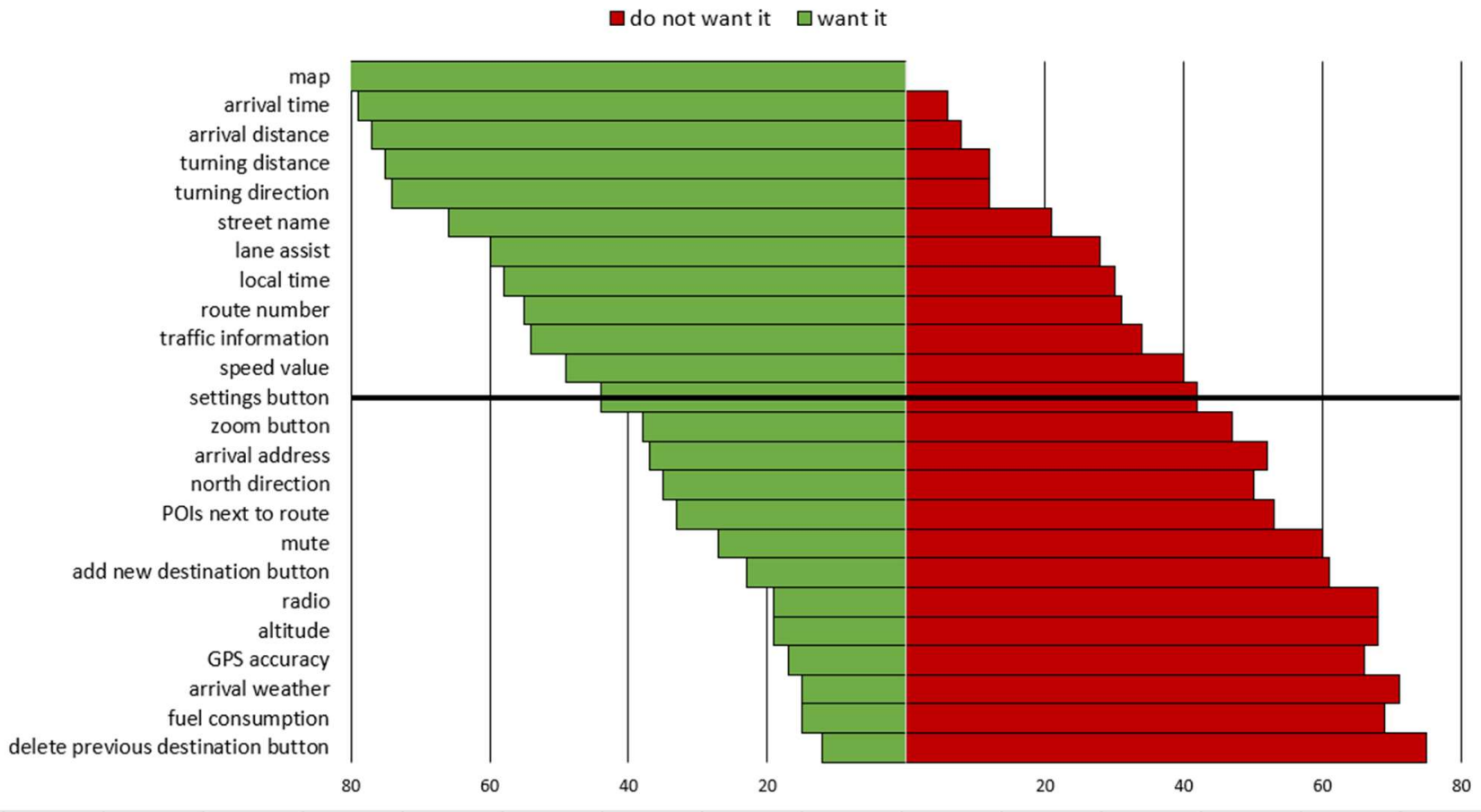

Figure 15. User requirements for the interface

\section{Discussion}

It is very important to choose wisely what features and buttons are on the map view. If the right tools appear on the screen, it greatly increases the driving safety. We asked the users what they saw on the screen right then, and what they want to see. The answers were converted into four groups: someone has it and need it; has it but do not need it; does not have it but need it; and does not have it and does not want it. You can see them merged in Figure 15. The options provided in the questionnaire are nicely separated from volition; the settings button (marked with black line) is the only one that has the same number $(+/-$ $10 \%$ ) of yes and no. Most people are happy with their current GPS, but there are surprising answers. Based on this part of the questionnaire, it is possible to create the map view of the "perfect" built-in GPS. Beyond this visualization, it would be worthwhile to internationalize the questionnaire.

\section{Conclusions}

Although only a few selected topics have been presented, some conclusions can already be drawn from them. As expected, average ages of the Hungarian cars are older than the EU's average. After that it is not surprising that only $21 \%$ has new car. Cars that have built-in GPS (17\% of all respondents) are significantly younger. Most people 
had problems with the price of GPS and not being up to date. In non-everyday situations, the number of GPS users is increasing, but it is used by more than half of the respondents in the daily trips (commuting, work routes). There are obvious differences between men and women in their driving and GPS usage habits. Women are more prescient: they plan the trips most often, they prefer the safer way, and stop at the red light to operate the GPS. On the other hand, they do not use it so often as men. There is no growing or declining trend related to age. The older age group uses the GPS with the same confidence and frequency as the younger ones, and even more!

\section{References}

ACEA. (2018). ACEA Report Vehicles in use Europe 2018. European Automobile Manufacturers Association, 1-19. Retrieved from https://www.acea.be/uploads/statistic_documents/ACE A_Report_Vehicles_in_use-Europe_2017.pdf

Forlizzi, J. and Battarbee, K. (2004). Understanding experience in interactive systems. In Proceedings of the 2004 conference on Designing Interactive Systems (DIS 04): processes, practices, methods, and techniques (New York: ACM), p. 261.

Alben, L. (1996). Quality of experience: defining the criteria for effective interaction design. Interactions, 3, pp. 11-15.

Roto, V. (2006). User experience building blocks. In Law, E., Hvannberg, E., and Hassenzahl, M., editors, Proceedings of the The Second COST294-MAUSE International Open Workshop: User ExperienceTowards a Unified View, pp. 124-128.

Hassenzahl, M. and Tracinsky, N. (2006). User experience - a research agenda. Behavior and Information Technology 25(2), pp. 91-97

Leshed, G, Velden, T., Rieger, O., Kot, B., Sengers, P. (2008). In-car GPS navigation: engagement with and disengagement from the environment. In Proceedings of the SIGCHI Conference on Human Factors in Computing Systems (CHI '08). ACM, New York, NY, USA, pp. $1675-1684$

Varga, G. (2011): Navigációs rendszerek használata: felhasználói szokások és interakciók vizsgálata (manuscript)

Vörös, F., Van Wyk de Vries, B., Székely, B. (2018). Geomorphometric descriptive parameters of scoria cones from different DTMs: A resolution invariance study. In 7th INTERNATIONAL CONFERENCE ON CARTOGRAPHY \& GIS: Proceedings, Vol. 1 and Vol. 2. (ed. Temenoujka Bandrova) 